\title{
Linguiças frescais elaboradas com carne de avestruz: características físico-químicas
}

\author{
Ostrich Brazilian sausage: physicochemical characteristics
}

\author{
Rafael Soares Nascimento ${ }^{\mathrm{I}}$ Ana Beatriz Monteiro Fonseca ${ }^{\mathrm{II}}$ Robson Maia Franco ${ }^{\mathrm{III}}$ \\ Zander Barreto Miranda ${ }^{\mathrm{III}}$
}

\section{RESUMO}

A carne de avestruz por apresentar baixos conteúdos de colesterol, gordura intramuscular e altas percentagens de ácidos graxos poli-insaturados ômega-3 é considerada uma carne vermelha saudável e de grande aceitação junto aos consumidores. Considerando que os recortes resultantes da desossa das carcaças de avestruz são partes consideradas menos nobres, desenvolveu-se a produção de três formulações de linguiça frescal tendo como base a carne de avestruz (recortes e aparas), promovendo as análises físico-químicas e colorimétricas com o objetivo caracterizar o perfil físico-químico e colorimétrico dessas diferentes formulações. As três formulações se encontraram dentro dos padrões físico-químicos estipulados pela legislação brasileira (BRASIL, 2000) e não apresentaram diferença significativa entre si, com exceção do teor de cinzas, mais alto nas linguiças mistas. Na análise do teor de pH, observou-se diferença significativa entre os tratamentos, com $\mathrm{pH}$ maior nas linguiças puras em relação às mistas. As linguiças puras foram mais escuras e vermelhas que as mistas, sendo que a mista de avestruz, suína e frango foi a mais clara. As linguiças frescais puras ou mistas elaboradas com carne de avestruz são uma opção viável de produção e comercialização, podendo concorrer no mercado com as linguiças tradicionais com perspectiva de êxito.

Palavras-chave: avestruz, carne, embutidos, linguiça, análise físico-química.

\section{ABSTRACT \\ Ostrich's meat has low contents of colestherol and intramuscular fat and high percentages of poliunsaturated fat}

acid $\omega-3$ so it's known as a healthy red meat with consumer great acceptability. Considering that ostrich trim (meat resulting from boning) is considered a less noble part, three formulations of ostrich (trim) Brazilian sausage were produced. Physicochemical analyses and color evaluation $\left(L^{*}, a^{*}, b^{*}\right)$ were made to determine formulations' physicochemical characteristics and colorimetric profile. The physicochemical results of all formulations were in accord with the Brazilian legislation pattern's (BRASIL, 2000) and no differences $(P>0,05)$ between formulations have been found except in the ash content, higher in mixed sausages. Differences $(P>0,05)$ have been found also between the $\mathrm{pH}$ of the treatments, which increased with the heightening of the percentage of ostrich meat in formulation. The sausages formulated with $100 \%$ ostrich meat were darker and redder in appearance than the mixed ones. The mixed of ostrich, pork and chicken Brazilian sausage were the lightest. The Brazilian sausages prepared with ostrich meat, pure or mixed, are a viable option for production and sale, and can be placed in the market and compete with the traditional sausages with the prospect of being successful.

Key words: ostrich, meat, brazilian sausage, physicochemical analyses, sausages.

\section{INTRODUÇÃO}

A carne de avestruz é conhecida como uma iguaria, geralmente servida cozida, grelhada ou seca, biltong, carne curada seca da África do Sul semelhante ao Jerked Beef (BÖHME et al., 1996). É considerada e comercializada nas sociedades ocidentais como uma

'Programa de Pós-graduação em Medicina Veterinária, Área de concentração em Higiene Veterinária e Processamento Tecnológico de Produtos de Origem Animal, Universidade Federal Fluminense (UFF), Rua Vital Brasil Filho, 64, Vital, 24230-340, Niterói, RJ, Brasil. E-mail: rafaelsnas@gmail.com. Autor para correspondência.

"Departamento de Estatística, Instituto de Matemática, UFF, Niterói, RJ, Brasil.

IIIDepartamento de Tecnologia de Alimentos, Faculdade de Veterinária, UFF, Niterói, RJ, Brasil. 
alternativa saudável às demais carnes vermelhas devido às suas propriedades nutricionais: baixos conteúdos de colesterol e de gordura intramuscular e alta porcentagem de ácidos graxos poli-insaturados ômega-3 (FISHER et al., 2000; GONZÁLES-MONTALVO et al., 2007).

$\mathrm{O}$ pH da carne de avestruz é relativamente alto, tornando essa carne ideal para a industrialização, já que sua capacidade de retenção de água é alta, sendo uma boa característica na elaboração de produtos cárneos (FERNÁNDEZ-LÓPEZ et al., 2003; FISHER et al., 2000).

Considerando as suas características, a carne de avestruz tem oferecido diversas alternativas na elaboração de produtos de salsicharia, embutidos ou não. Diversos pesquisadores promoveram estudos sobre a produção tecnológica de mortadela, salame, presunto, salsicha, hambúrguer em diferentes formulações com outras carnes de animais de açougue (bovinos, aves, suínos).

A linguiça é o produto cárneo industrializado, obtido de carnes de animais de açougue, adicionado ou não de tecidos adiposos, ingredientes, embutido em envoltório natural ou artificial e submetido ao processo tecnológico adequado. Tem como ingredientes obrigatórios a carne das diferentes espécies de animais de açougue e sal e, como ingredientes opcionais, gordura, água, proteína vegetal e/ou animal, açúcares, plasma, aditivos intencionais, aromas, especiarias e condimentos. Apresenta textura, cor, sabor e odor característicos (BRASIL, 2000) e é um dos produtos cárneos mais produzidos no Brasil, provavelmente, porque sua produção, além de não exigir tecnologia sofisticada, utiliza poucos aparelhos e que são de baixo custo (MILANI et al., 2003).

Segundo o Regulamento Técnico de Identidade e Qualidade de Linguiça, Anexo III da Instrução Normativa no $\mathbf{4}$, de 31 de março de 2000, do Ministério da Agricultura, Pecuária e Abastecimento (MAPA) (BRASIL, 2000), as características físicoquímicas das linguiças frescais deve ser: Umidade (máx): 70\%; Gordura (máx): 30\%; Proteína (mín): 12\%; Cálcio (base seca) (máx): 0,1\%.

Considerando que as linguiças apresentam grande aceitação junto ao consumidor e com o objetivo de destinar o melhor aproveitamento aos recortes e aparas de carne de avestruz, provenientes da desossa e, por isso, considerados partes menos nobres, foram produzidas três formulações de linguiça, tendo como base a carne de avestruz (recortes e aparas). Estas foram submetidas às avaliações físico-químicas e colorimétricas para estabelecer sua composição em relação a proteínas, lipídeos, umidade e sais minerais, pH e caracterização colorimétrica.

\section{MATERIAL E MÉTODOS}

Obtenção das carnes

A carne de avestruz utilizada foi obtida a partir de aparas de carne de avestruzes abatidas com idade entre 12 e 14 meses em matadouro-frigorífico sob o Serviço de Inspeção Federal. Após terem sido resfriadas à temperatura de $2^{\circ} \mathrm{C} \mathrm{em} 24$ horas, essas carnes foram removidas das carcaças das aves 24 horas após o abate, embaladas, encaixotadas e congeladas à $-35^{\circ} \mathrm{C}$, sendo estocadas à temperatura de $-18^{\circ} \mathrm{C}$.

A carne suína utilizada foi obtida do corte lombo, também foi utilizado toucinho sem pele. A carne de frango utilizada foi obtida dos cortes de coxa e sobrecoxa. Ambas as matérias primas foram obtidas no comércio varejista, procedentes de matadourosfrigoríficos sob Serviço de Inspeção Oficial e foram conservadas congeladas a $-18^{\circ} \mathrm{C}$.

Para elaboração das linguiças, as carnes foram submetidas ao processo de descongelamento lento em refrigerador à temperatura de $7^{\circ} \mathrm{C}$ em um período de 18 horas.

Elaboração, embalagem a vácuo e conservação das linguiças

Foram elaboradas três formulações com os seguintes percentuais de carne: A $-100 \%$ carne de avestruz; $\mathrm{B}-75 \%$ carne de avestruz $+25 \%$ carne suína; C $-50 \%$ carne de avestruz $+25 \%$ carne suína $+25 \%$ carne de frango.

As carnes e o toucinho foram cortados manualmente, com auxílio de facas de aço inoxidável. Os cubos de carne e toucinho foram cominuídos, separadamente, em moedor de carnes de $106 \mathrm{~mm}$ (Ibrasmack ${ }^{\circledR}$, MC 106, Ribeirão Pires, Brasil), utilizandose disco de $10 \mathrm{~mm}$, sendo colocados em recipientes próprios. As porções de cada ingrediente da formulação foram colocadas na misturadeira sem vácuo (Incomaf $^{\circledR}$, MT 200, Itaquaquecetuba, Brasil), sendo misturadas mecanicamente, de forma homogênea, por um período de 15 minutos, levando à formação de uma massa cárnea uniforme, que foi imediatamente embutida em tripa natural de suíno calibre $30 / 32$ por meio da utilização de uma embutideira (Incomaf ${ }^{\circledR}$, RS 1040, Itaquaquecetuba, Brasil), seguida de amarração dos gomos em tamanhos de $10 \mathrm{~cm}$. Foram embaladas a vácuo na embaladora a vácuo (Selovac ${ }^{\circledR}, 300$ B, São Paulo, Brasil).

As amostras foram, então, acondicionadas em bolsas isotérmicas e transportadas até o local do armazenamento, sendo estocadas em refrigerador doméstico (Brastemp ${ }^{\circledR}$, Brastemp 360, São Paulo, Brasil) à temperatura de $5 \pm 2^{\circ} \mathrm{C}$ até o dia seguinte, quando foram realizadas as análises. 
Análises físico-químicas

Foram analisados os teores de umidade, proteína, lipídeos e $\mathrm{pH}$, conforme a metodologia descrita na Instrução Normativa no 20, de 21 de julho de 1999, do MAPA (BRASIL, 1999) e os teores de TBARS foram verificados conforme descrito por TARLADGIS et al. (1960), sendo realizadas cinco repetições de cada parâmetro para cada análise.

Análise instrumental de cor

Para realização da análise instrumental de cor, as amostras de linguiça foram fatiadas e homogeneizadas em placas de Petri e os valores de luminosidade $\left(\mathrm{L}^{*}\right)$, vermelho ( $\mathrm{a}^{*}, \pm$ vermelho-verde) e amarelo ( $b^{*}, \pm$ amarelo-azul) foram determinados com a utilização de colorímetro Minolta modelo CR 200b. A calibração foi feita antes de cada teste (MOTZER et al., 1998). Foram realizadas cinco medições para a análise de cada parâmetro.

\section{Avaliação estatística}

Para avaliação estatística, foi realizado o Delineamento Inteiramente Casualizado, utilizando-se 15 amostras no total, cinco amostras por formulação.

Para as variáveis, foi realizada análise descritiva para determinação da média, desvio-padrão, valores mínimos e máximos. Para indicar diferença significativa $(\mathrm{P}<0,05)$ entre tratamentos, foi utilizado o teste de Kruskal-Wallis. Quando este indicou diferença entre os tratamentos, foi realizado o teste de MannWhitney, o qual revelou entre quais tratamentos houve diferença e se esta foi significativa.

Para realização das análises estatísticas, foi utilizado o programa de computador SPSS, versão 14, para Windows.

\section{RESULTADOS E DISCUSSÃO}

Quanto aos teores de umidade, proteína e lipídeos, as formulações não apresentaram diferença significativa entre si (Tabela 1) e se encontraram dentro dos padrões estabelecidos pelo Regulamento Técnico de Identidade e Qualidade da Linguiça (BRASIL, 2000): Umidade (máx): 70\%; Proteína (mín): 12\%; e Gordura (máx): $30 \%$. No que concerne ao teor de umidade, CAVALHEIROet al. (2010), FERNÁNDEZ-LÓPEZ et al. (2003; 2006) e HAUTRIVE et al. (2008) também não observaram variação entre as diferentes formulações estudadas. Segundo FERNÁNDEZ-LÓPEZ et al. (2003), é bem conhecida a relação inversa entre teor de gordura e teor de umidade. Com relação ao teor de proteína, CAVALHEIROet al. (2010), FERNÁNDEZ-LÓPEZ et al. (2003; 2006), HAUTRIVE et al. (2008) e McKENNA et
Tabela 1 - Composição físico-química (\%), pH e valores de TBARS das formulações de linguiças elaboradas com carne de avestruz, obtidas a partir de 5 repetições por parâmetro.

\begin{tabular}{llll}
\hline & Fórmula A & Fórmula B & Fórmula C \\
\hline Umidade (\%) & $66,2 \pm 1,08$ & $66,8 \pm 1,02$ & $66,18 \pm 1,73$ \\
Proteína (\%) & $18,81 \pm 1,34$ & $17,57 \pm 0,9$ & $16,88 \pm 0,48$ \\
Lipídeos (\%) & $13,11 \pm 1,3$ & $14,96 \pm 2,45$ & $14,15 \pm 2,22$ \\
Cinzas (\%) & $2,96 \pm 0,12^{\mathrm{a}}$ & $3,21 \pm 0,07^{\mathrm{b}}$ & $3,19 \pm 0,04^{\mathrm{b}}$ \\
pH & $6,57 \pm 0,01^{\mathrm{a}}$ & $6,49 \pm 0,03^{\mathrm{b}}$ & $6,38 \pm 0,02^{\mathrm{c}}$ \\
TBARS & $0,96 \pm 0,13^{\mathrm{a}}$ & $1,06 \pm 0,06^{\mathrm{a}}$ & $0,81 \pm 0,04^{\mathrm{b}}$ \\
\hline
\end{tabular}

Fórmula A, 100\% carne de avestruz; Fórmula B, 75\% carne de avestruz, 25\% suína; Fórmula C, 50\% carne de avestruz, 25\% suína e $25 \%$ frango. Valores na mesma linha com diferentes letras são diferentes estatisticamente $(\mathrm{P}<0,05)$.

al. (2003) observaram maiores teores nas formulações com maiores percentagens de carne de avestruz, ou nas formulações com carne de avestruz em relação à formulações com carnes de outras espécies de animais de açougue. Segundo McKENNA et al. (2003), os produtos contendo carne de avestruz continham maiores teores de proteína, resultado contrário ao observado por HAUTRIVE et al. (2008). No presente trabalho, houve a tendência de aumento da proteína acompanhando o aumento na proporção de carne de avestruz da formulação. Quanto ao teor de lipídeos, CAVALHEIRO et al. (2010) também não observaram diferença entre formulações, por outro lado, FERNÁNDEZ-LÓPEZet al. (2003; 2006), , HAUTRIVE et al. (2008) e McKENNA et al. (2003) observaram diferenças. McKENNA et al. (2003) afirmaram que os produtos elaborados com carne de avestruz tiveram menores teores de lipídeos, ao que concordam CAVALHEIRO et al. (2010), FERNÁNDEZ-LÓPEZ et al. (2003) e HAUTRIVE et al. (2008). Os valores acima de $13,11 \%$ de gordura nas linguiças elaboradas com carne de avestruz no presente trabalho, provavelmente, se devem ao toucinho utilizado na sua formulação, visto que, segundo PALEARI et al. (1998), a carne de avestruz possui 1,6\% de gordura e, segundo FISHER et al. (2000), possui $3,57 \%$.

As formulações mistas apresentaram maiores teores de cinzas que a formulação pura. CAVALHEIRO et al. (2010), FERNÁNDEZ-LÓPEZ et al. (2003; 2006) não encontraram diferenças significativas entre as fórmulas. Os altos valores de cinzas, comparados com os valores da carne de avestruz, entre $1,07 \%$, observados por SALES \& HAVES (1996), e $2,42 \%$, por KARAKÖK et al. (2010), provavelmente se devem à utilização de cloreto de sódio, sais de cura (nitrito), condimentos e especiarias na formulação das 
linguiças, em acordo com o que afirmaram FERNÁNDEZ-LÓPEZ et al. (2003; 2006), e FISHER, HOFFMAM \& MELLETT (2000).

$\mathrm{O} \mathrm{pH}$ foi maior quanto maior o percentual de carne de avestruz na formulação. Isso provavelmente se deve ao fato de a carne de avestruz possuir um $\mathrm{pH}$ maior que outras carnes, em acordo com o que relataram CAVALHEIRO et al. (2010), FERNÁNDEZ-LÓPEZ et al. (2006) e HAUTRIVE et al. (2008). Entretanto, FERNÁNDEZ-LÓPEZ et al. (2003) não observou o mesmo comportamento.

Quanto ao Teor de Substâncias Reativas ao Ácido Tiobarbitúrico (TBARS), a formulação C obteve o valor mais baixo e diferiu significativamente das demais formulações.

A formulação $C$ apresentou a maior luminosidade $\left(\mathrm{L}^{*}\right)$, seguido pela formulação $B$, apresentando a formulação A o menor valor (Tabela 2). $\mathrm{O}$ resultado se encontra de acordo com o observado FERNÁNDEZ-LÓPEZ et al. (2003). Segundo COOPER \& HORBAÑCZUK (2002), a carne de avestruz possui uma coloração mais escura, mesmo quando comparada à carne bovina, devido ao alto conteúdo de heme e ao efeito do alto $\mathrm{pH}$, que varia de 5,8 a 6,2, na retenção de água, resultando em menor capacidade de refletir a luz. Entretanto, FERNÁNDEZ-LÓPEZ et al. (2006) não encontraram diferença na luminosidade entre formulações de hambúrguer. O motivo para os valores observados no presente trabalho serem mais altos que os observados em carne e outros produtos elaborados com carne de avestruz por FERNÁNDEZ-LÓPEZ et al. (2008), OTREMBA et al. (1999), SEYDIM et al. (2006), FERNÁNDEZ-LÓPEZ et al. (2006), HOFFMAN \& MELLETT (2003) e FISHER et al. (2000) provavelmente se deve à utilização de toucinho, que, como afirmaram FISHER et al. (2000), por ser branco, acarreta em um aumento dessa característica, luminosidade, uma vez que a carne de avestruz é tipicamente escura.

Tabela 2 - Resultados referentes ao perfil colorimétrico das formulações de linguiças elaboradas com carne de avestruz, obtidas a partir de cinco repetições por parâmetro

\begin{tabular}{cccc}
\hline & Fórmula A & Fórmula B & Fórmula C \\
\hline $\mathrm{L}^{*}$ & $47,54 \pm 1,68^{\mathrm{a}}$ & $50,21 \pm 1,06^{\mathrm{a}}$ & $54,19 \pm 1,13^{\mathrm{b}}$ \\
$\mathrm{a}^{*}$ & $28,44 \pm 0,39^{\mathrm{a}}$ & $26,93 \pm 0,21^{\mathrm{b}}$ & $24,61 \pm 0,78^{\mathrm{c}}$ \\
$\mathrm{b}^{*}$ & $10,53 \pm 0,24^{\mathrm{a}}$ & $10,73 \pm 0,35^{\mathrm{a}}$ & $9,94 \pm 0,21^{\mathrm{b}}$ \\
\hline
\end{tabular}

Fórmula A, 100\% carne de avestruz; Fórmula B, 75\% carne de avestruz, 25\% suína; Fórmula C, 50\% carne de avestruz, 25\% suína e $25 \%$ frango. Valores na mesma linha com diferentes letras são diferentes estatisticamente $(\mathrm{P}<0,05)$.
A fórmula $\mathrm{A}$ foi a que obteve maiores valores de $a^{*}$, mostrando-se mais vermelha, seguida das fórmulas B e C. O resultado está em acordo com FISHER et al. (2000), ao afirmarem que a carne de avestruz parece ser mais vermelha que a carne suína e de frango e com FERNÁNDEZ-LÓPEZet al. (2003), ao reportarem que a carne de avestruz parece mais vermelha até que a carne bovina.

A formulação B obteve os maiores valores de b*, sendo mais amarelo, e a formulação C obteve os menores. A fórmula A obteve valores intermediários e não apresentou diferença significativa em relação a ambos. FERNÁNDEZ-LÓPEZ et al. (2003) também encontrou diferença entre fórmulas, no caso, mortadela Bolonha a base de carne de avestruz e a base de carne bovina. Também foram observados por FERNÁNDEZLÓPEZ et al. (2006), em hambúrgueres, onde os hambúrgueres $100 \%$ avestruz e $70 \%$ avestruz e $30 \%$ bovina apresentaram valores menores em relação ao hambúrguer $70 \%$ avestruz e 30\% suína, contrariamente ao presente estudo, quando comparadas com linguiças frescais a base de carne de avestruz.

\section{CONCLUSÃO}

As três formulações de linguiças frescais elaboradas com carne de avestruz se apresentaram físico-quimicamente dentro dos padrões estipulados para linguiças frescais no Regulamento Técnico de Identidade e Qualidade de Linguiça, Anexo III da Instrução Normativa ${ }^{\circ}$ 4, de 31 de março de 2000, do Ministério da Agricultura, Pecuária e Abastecimento (MAPA) (BRASIL, 2000). As formulações apresentaram maiores teores de proteínas e menores teores de lipídeos que os padrões estabelecidos pela Instrução Normativa, atendendo às exigências do consumidor no que se refere a alimentos saudáveis, nos aspectos nutricionais.

$\mathrm{O}$ pH aumentou, acompanhando o aumento do percentual de carne de avestruz nas formulações.

As linguiças puras foram mais escuras e vermelhas que as mistas, sendo a mista de carne de avestruz, suína e frango a mais clara e menos vermelha.

As linguiças frescais puras ou mistas elaboradas com carne de avestruz são uma opção viável de produção e comercialização, podendo concorrer no mercado com as linguiças tradicionais com perspectiva de êxito.

\section{AGRADECIMENTOS}

À Coordenação de Aperfeiçoamento de Pessoal de Nível Superior (CAPES), pelo apoio financeiro durante o curso de mestrado. Ao Prof. Mauro Carlos Lopes Souza, à empresa 
Avestrino, ao Serviço Nacional de Aprendizagem Industrial (SENAI), unidade de Vassouras, Estado do Rio de Janeiro, e à Empresa de Pesquisa Agropecuária do Estado do Rio de Janeiro (PESAGRO-RIO), Laboratório de Controle de Qualidade, pelo apoio prestado à realização do presente trabalho.

\section{REFERÊNCIAS}

BÖHME, H.M. et al. Production of salami from ostrich meat with strains of Lactobacillus sake, Lactobacillus curvatus and Micrococcus sp. Meat Science, v.44, n.3, p.173-180, 1996. Disponível em: <http://dx.doi.org/10.1016/S03091740(96)00083-6>. Acesso em: 6 abr. 2011. doi: 10.1016/ S0309-1740(96)00083-6.

BRASIL. Instrução Normativa n.4, de 31 de março de 2000. Aprova os regulamentos técnicos de identidade e qualidade de carne mecanicamente separada, de mortadela, de linguiça e de salsicha. Diário Oficial [da] República Federativa do Brasil, Brasília, DF, p.6, 05 abr. 2000. Seção 1.

Instrução Normativa n.20 de 21 de julho de 1999. Métodos analíticos oficiais para controle de produtos de origem animal e seus ingredientes. Ministério da Agricultura e Abastecimento. Diário Oficial [da] República Federativa do Brasil, Brasília, DF, p.10, 27 jul. 1999. Seção 1.

CAVALHEIRO, C.P. et al. Características físico-químicas de embutido curado fermentado com adição de carne de avestruz associada à de suíno. Ciencia Rural, v.40, n.2, p.447-452, 2010. Disponível em: <http://dx.doi.org/10.1590/S010384782010000200030>. Acesso em: 6 abr. 2011. doi: 10.1590/ S0103-84782010000200030.

COOPER, R.G.; HORBAÑCZUK, J.O. Anatomical and physiological characteristics of ostrich (Struthio camelus var. domesticus) meat determine its nutritional importance for man. Animal Science Journal, v.73, p.167-173, 2002. Disponível em: 〈http://dx.doi.org/ 10.1046/j.1344-3941.2002.00024.x>. Acesso em: 6 abr. 2011. doi: 10.1046/j.13443941.2002.00024.x.

FERNÁNDEZ-LÓPEZ, J. et al. Physical, chemical, and sensory properties of bologna sausage made with ostrich meat. Journal of Food Science, v.68, n.4, p.1511-1515, 2003. Disponível em: <http://dx.doi.org/ 10.1111/j.1365-2621.2003.tb09675.x〉. Acesso em: 6 abr. 2011. doi: 10.1111/j.1365-2621.2003.tb09675.x.

FERNÁNDEZ-LÓPEZ, J. et al. Quality characteristics of ostrich (Struthio camelus) burgers. Meat Science, v.73, p.295303, 2006. Disponível em: <http://dx.doi.org/10.1016/ j.meatsci.2005.12.011>. Acesso em: 6 abr. 2011. doi:10.1016/ j.meatsci.2005.12.011.

FERNÁNDEZ-LÓPEZ, J. et al. Effect of packaging conditions on shelf-life of ostrich steaks. Meat Science, v.78, n.1-2, p.143-152, 2008. Disponível em: <http://dx.doi.org/10.1016/ j.meatsci.2007.09.003>. Acesso em: 6 abr. 2011. doi:10.1016/ j.meatsci.2007.09.003.

FISHER, P. et al. Processing and nutritional characteristics of value added ostrich products. Meat Science, v.55, p.251-254, 2000. Disponível em: <http://dx.doi.org/10.1016/S0309-
1740(99)00139-4>. Acesso em: 6 abr. 2011. doi:10.1016/ S0309-1740(99)00139-4.

GONZÁLES-MONTALVO, B. et al. Influence of oxygen exclusion and temperature on pathogenic bacteria levels and sensory characteristics of packed ostrich steaks throughout refrigerated storage. Meat Science, v.76, p.201-209, 2007. Disponível em: <http://dx.doi.org/ 10.1016/j.meatsci.2006.10.025>. Acesso em: 6 abr. 2011. doi: 10.1016/j.meatsci.2006.10.025.

HAUTRIVE, T.P. et al. Análise físico-química e sensorial de hambúrguer elaborado com carne de avestruz. Ciência e Tecnologia de Alimentos, v.28, supl, p.95-101, 2008. Disponível em: <http:/ /dx.doi.org/10.1590/S0101-20612008000500016>. Acesso em: 6 abr. 2011. doi: 10.1590/S0101-20612008000500016.

HOFFMAN, L.C.; MELLETT, F.D. Quality characteristics of low fat ostrich meat patties formulated with either pork lard or modified corn starch, soya isolate and water. Meat Science, v.65, n.2, p.869-875, 2003. Disponível em: <http://dx.doi.org/ 10.1016/S0309-1740(02)00293-0>. Acesso em: 06 abr. 2011. doi: 10.1016/S0309-1740(02)00293-0.

MASTROMATTEO, M. et al. Microbiological characteristics of poultry patties in relation to packaging atmospheres. International Journal of Food Science and Technology, v.44, n.12, p.2620-2628, 2009. Disponível em: <http:// dx.doi.org/10.1111/j.1365-2621.2009.02093.x>. Acesso em: 6 abr. 2011. doi: 10.1111/j.1365-2621.2009.02093.x.

MCKENNA, D.R. et al. Consumer acceptability of processed ostrich meat products. Journal of Muscle Foods, v.14, n.2, p.173-179, 2003. Disponível em: <http://dx.doi.org/ 10.1111/ j.1745-4573.2003.tb00698.x>. Acesso em: 6 abr. 2011. doi: 10.1111/j.1745-4573.2003.tb00698.x.

MILANI, L.I.G. et al. Bioproteção de linguiça de frango. Ciência e Tecnologia de Alimentos, v.23, n.2, p.161-166, 2003. Disponível em: <http://dx.doi.org/10.1590/S010120612003000200010>. Acesso em: 6 abr. 2011. doi: 10.1590/ S0101-20612003000200010.

MOTZER, J.A. et al. Quality of restructured hams manufactured with PSE pork as affected by water binders. Journal of Food Science, v.63, n.6; p.1007-1011, 1998. Disponível em: <http:/ /dx.doi.org/10.1111/j.1365-2621.1998.tb15843.x>. Acesso em: 6 abr. 2011. doi: 10.1111/j.1365-2621.1998.tb15843.x.

OTREMBA, M.M. et al. Refrigerated shelf life of vacuumpackaged, previously frozen ostrich meat. Meat Science, v.52, n.3, p.279-283, 1999. Disponível em: <http://dx.doi.org/ 10.1016/S0309-1740(99)00003-0>. Acesso em: 6 abr. 2011. doi:10.1016/S0309-1740(99)00003-0.

SEYDIM, A.C. et al. Effects of packaging atmospheres on shelf-life quality of ground ostrich meat. Meat Science, v.73, n.3, p.503-510, 2006. Disponível em: <http://dx.doi.org/ 10.1016/j.meatsci.2006.01.010>. Acesso em: 6 abr. 2011. 10.1016/j.meatsci.2006.01.010.

TARLADGIS, B.C. et al. A destillation method for the quantitative determination of malonaldethyde in rancid foods. Journal of the American Oil Chemists Society, v.37, p.44-48, 1960. 